\title{
Hardware removal rates after surgical treatment of proximal femur fractures
}

\author{
Nationwide trends in Finland in 1997-2016
}

Ville T. Ponkilainen ${ }^{1}$ (1) - Tuomas T. Huttunen ${ }^{2,3,4} \cdot$ Pekka Kannus $^{1,2} \cdot$ Ville M. Mattila $^{1,2,5}$

Received: 4 December 2019 / Published online: 21 January 2020

(c) The Author(s) 2020

\begin{abstract}
Background Various internal fixation methods have been used to treat proximal femur fractures and occasionally the fixation material is removed. However, nationwide trends of hardware removals are not known. Thus, this study investigated the hardware removal rates after proximal femur fractures in Finland during 1997-2016.

Materials and methods Finnish adults aged 18 years or older in 1997-2016 formed the basic study population. From the National Hospital Discharge Register patients with trochanteric femur fracture treated with an intramedullary nail (IMN) or dynamic hip screw (DHS), and patients with femoral neck fracture treated with screw fixation, were included. Hardware removal and secondary prosthesis rates were assessed.

Results Altogether 41,253 patients underwent proximal femoral fracture fixation surgery in Finland in 1997-2016. Of these, 16,152 were DHS surgery and 15,724 IMN surgery and 8491 underwent screw operation of femoral neck fracture. The total removal rates of DHS and IMN were 5.5\% and 5.4\%. The total removal rate of screw fixations of the femoral neck was higher, 18.5\%. The total removal rates during the first 3 years after the IMN more than halved in 1997-2013, from 7.6\% to $3.7 \%$, whereas the removal rate of the DHS or screw fixation of femoral neck fractures did not show consistent trend. The rate of secondary prosthesis operations following DHS and IMN was low (1.8\% for both). This was in clear contrast to the prosthesis rate following screw fixations of the femoral neck (7.2\%).

Conclusions IMN operations largely replaced DHS operations in trochanteric fractures of the proximal femur in Finland in 1997-2016. The removal and secondary prosthesis rates of the DHS and IMN were clearly lower than the corresponding rates after screw fixations of the femoral neck fracture.

Level of evidence III, Epidemiologic study.
\end{abstract}

Keywords Fixation $\cdot$ Material $\cdot$ Removal $\cdot$ Secondary $\cdot$ Endoprosthesis

Ville T. Ponkilainen

ville.ponkilainen@tuni.fi

Tuomas T. Huttunen

tuomas.huttunen@tuni.fi

Pekka Kannus

pekka.kannus@tuni.fi

Ville M. Mattila

ville.mattila@tuni.fi

1 Department of Orthopaedics and Traumatology, Tampere

University Hospital, Kuntokatu 2, 33520 Tampere, Finland
2 Faculty of Medicine and Health Technology, Tampere University, Tampere, Finland

3 Department of Emergency, Anesthesia and Pain Medicine, Tampere University Hospital, Tampere, Finland

4 The Division of Orthopedics and Biotechnology, Department of Clinical Science, Intervention and Technology (CLINTEC), Karolinska Institutet, Stockholm, Sweden

5 COXA Hospital for Joint Replacement, Tampere, Finland 


\section{Introduction}

Fractures of the proximal femur are one the most common age-related fractures in older adults and in entire populations they represent the third most common fracture type after distal radius and metacarpal fractures [12]. Proximal femur fractures are very costly $[18,36,43]$ with high postfracture morbidity and mortality $[10,26]$. Women have an increased risk for these fractures and the fracture incidence increases with age, propensity to fall and reduced bone density [22, 23, 26, 29, 42].

The incidence of proximal femur fractures increased rapidly till the end of 1990 s, although there was notable variation between different countries [12, 23, 35, 40]. In the new millenium, the incidence has stabilized or even decreased $[13,16,22,25,30,45]$. The proportion of trochanter fractures from all proximal femur fractures has increased and this is especially true among older age groups [16, 33, 38, 39, 45].

Various fixation methods have been used in the treatment of trochanteric fractures [4, 7, 14, 46, 48]. Dynamic hip screw (DHS) has been the most preferable method for years [46], although intramedullary nail (IMN) has been adopted to routine use of these fractures as well [1, 8]. Recent meta-analyses have favored the use of IMN, since post-operative mobilization is faster with IMN than DHS [3, 24, 41].

The treatment of femoral neck fractures has remained controversial for decades [11]. Osteosynthesis with internal screw or pin fixation has been used in non-displaced or minimally displaced fractures while primary arthroplasty has been suggested for displaced fractures [37]. Recent meta-analyses have shown that arthroplasty is slightly superior when compared to internal screw fixation of these fractures [2, 32, 44].

Removal of fixation material has accounted for $5-15 \%$ of all orthopaedic surgeries and up to $30 \%$ of all elective orthopaedic surgeries [6, 47]. In Finland, this number has been $6.3 \%$ of all orthopaedic operations representing an incidence of 90 per 100,000 person-years [6]. Nevertheless, the removal of the fracture fixation material should not be a routine procedure [9]. These procedures cause unwanted health care costs and sick leaves, and they cause a risk for post-operative infections, wound healing problems, refractures, nerve damage, and long-term pain [9, $15,19]$. In general, the literature investigating fixation material removals is scarce and there are no evidencebased guidelines for fixation material removals and the removal policy varies widely among professionals [20].

The aim of this study was to investigate the fixation material removal rates after surgery for proximal femur fractures in Finland between 1997 and 2016.

\section{Methods}

Patient data were obtained from the Finnish National Hospital Discharge Register (FHDR) between 1997 and 2016. All adult patients aged 18 years or older were included into study. Patient characteristics, such as age, sex, primary and secondary diagnosis, and operations performed during the hospital stay, were obtained from the database. The coverage and accuracy of the database have been shown to be excellent [27, 34, 49]. The FHDR does not include co-morbidities and other risk factors for fractures; thus this study focused on incidence rates.

Patients were selected using the diagnoses which have been coded with the International Classification of Diseases, Tenth Revision (ICD-10). The diagnoses were then combined with the NOMESCO (Nordic Medico-Statistical Committee) classification procedure codes. Only patients with fractures treated with osteosynthesis were included. From Finnish NHDR, we included: Code S72.0 (Fracture of neck of femur), which was combined with NFJ50 (Internal fixation of fracture of neck of femur with nail or screw), and code S72.1 (Pertrochanteric fracture), which was combined with NFJ54 (Internal fixation of fracture of upper femur with intramedullary nail) or NFJ52 (Internal fixation of fracture of upper femur with screws and sideplate). Among these patients, all fixation material removals which were performed after the initial surgery were identified using the NOMESCO code NFU20 (Removal of internal fixation device from femur).

The delay between the primary procedure and removal of fixation material was calculated using the admission date between the two hospitalizations. If the same patient underwent multiple hospitalizations due to the same operation, only the first one was included, as we were unable to tell whether the second admission was due to a new fracture or a complication of the first proximal femur fracture. Patients who underwent multiple different primary hip operations were excluded, since we are unable to know which fixation material was removed. If a patient underwent removal and prosthesis operations during the same hospital stay, this hospital stay was considered as secondary prosthesis operation.

\section{Statistical analysis}

The incidence rates of the operations were based on the annual mid-populations, which were obtained from the Official Statistics of Finland. The incidences rates (per 100,000) were based on the entire adult population of Finland (persons 18 years of age or older). R (version 3.6.1) statistics software were used for statistical analysis. 


\section{Results}

Altogether 41,253 patients underwent proximal femoral fracture fixation operations in Finland between 1997 and 2016. Of these, 16,152 were DHS surgery and 15,724 IMN surgery due to trochanteric fracture of the femur, and 8491 underwent screw operation due to femoral neck fracture. During the study period DHS operations declined from 20 per 100,000 person-years in 1997 to 5 per 100,000 personyears in 2016 while IMN operations increased remarkably, from 5 per 100,000 person-years in 1997 to 29 per 100,000 person-years in 2016 (Fig. 1). Screw fixations of femoral neck fractures declined from 10 per 100,000 person-years in 1997 to 4 per 100,000 person-years in 2016.

The total removal rates of DHS and IMN were rather similar (5.5\% and 5.4\%). However, the total removal rate after screw fixations of femoral neck fracture was higher (18.5\%) (Table 1). The proportion of removals (without prosthesis) of DHS and IMN were relatively similar (3.7\% and $3.6 \%$ ). The similar removal rate after screw fixations of femoral neck fracture was higher $(11.3 \%)$ (Table 1).
Fig. 1 Incidence of screw fixation for femoral neck fracture, and dynamic hip screw (DHS) and intramedullary nail (IMN) fixation for trochanteric fracture of the proximal femur
Table 1 Total operations, secondary operations and removal delays after proximal femur fracture fixation operations

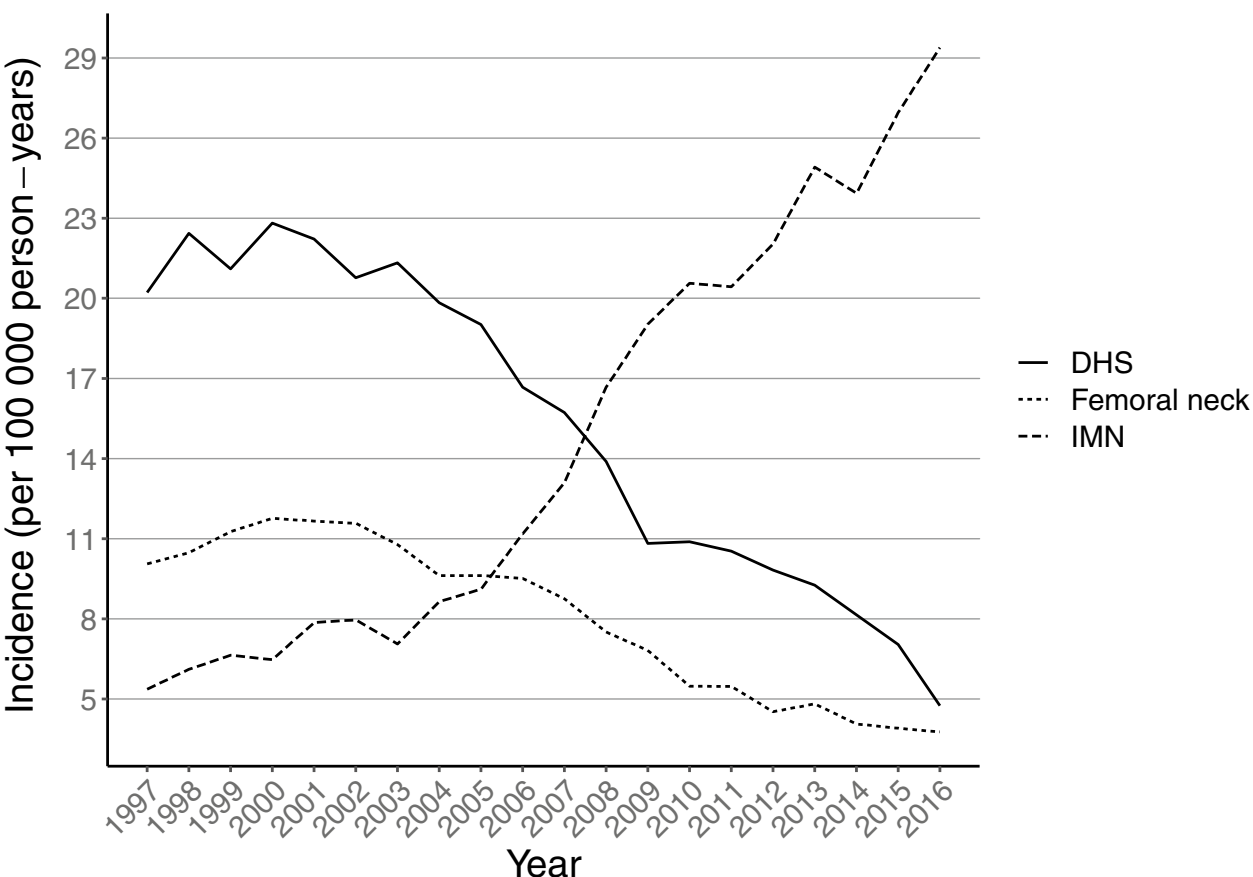

\begin{tabular}{|c|c|c|c|c|c|c|}
\hline & \multirow[t]{2}{*}{$n$} & \multirow[t]{2}{*}{$\%$} & \multicolumn{4}{|c|}{ Delay of the removal (years) } \\
\hline & & & $<1$ & $1-2$ & $2-5$ & $5+$ \\
\hline DHS & 16,152 & & & & & \\
\hline Secondary operations & 895 & 5.5 & 441 & 218 & 168 & 68 \\
\hline Removals & 598 & 3.7 & 270 & 160 & 123 & 45 \\
\hline Prosthesis & 297 & 1.8 & 171 & 58 & 45 & 23 \\
\hline IMN & 15,724 & & & & & \\
\hline Secondary operations & 844 & 5.4 & 461 & 192 & 143 & 48 \\
\hline Removals & 564 & 3.6 & 287 & 149 & 100 & 28 \\
\hline Prosthesis & 280 & 1.8 & 174 & 43 & 43 & 20 \\
\hline Screw fixation & 8491 & & & & & \\
\hline Secondary operations & 1574 & 18.5 & 814 & 420 & 245 & 95 \\
\hline Removals & 959 & 11.3 & 384 & 344 & 177 & 54 \\
\hline Prosthesis & 615 & 7.2 & 430 & 76 & 68 & 41 \\
\hline
\end{tabular}

$D H S$ dynamic hip screw for trochanteric fracture, $I M N$ intramedullary nail for trochanteric fracture, Screw fixation screw fixation for femoral neck fracture, Removals removal of fixation materials, Prosthesis removal of fixation materials and endoprosthesis 
Similarly, the rates of removals with secondary prosthesis operations following DHS and IMN were the same (1.8\%). This was in clear contrast to the rate following screw fixations of femoral neck fractures (7.2\%) (Table 1). The secondary prosthesis operations (which consisted of hardware removal and prosthesis surgery during the same hospital stay) were performed after a shorter time period than the fixation material removals (Fig. 2).

The total removal rates of the fixation material during the first three years after the IMN operation halved during the follow-up, from $7.6 \%$ (1997) to $3.7 \%$ (2013) (Fig. 3). The prosthesis implantation rates after the IMN surgery did not show any consistent trend during the study period.
Fig. 2 Boxplot of time intervals between the primary and the two secondary operations of the proximal femur fracture. The category "endoprosthesis" consisted of hardware removal and prosthesis surgery during the same hospital stay
Fig. 3 Total hardware removal and prosthesis rates during the first three years after intramedullary nail fixation of the trochanteric fracture of the proximal femur
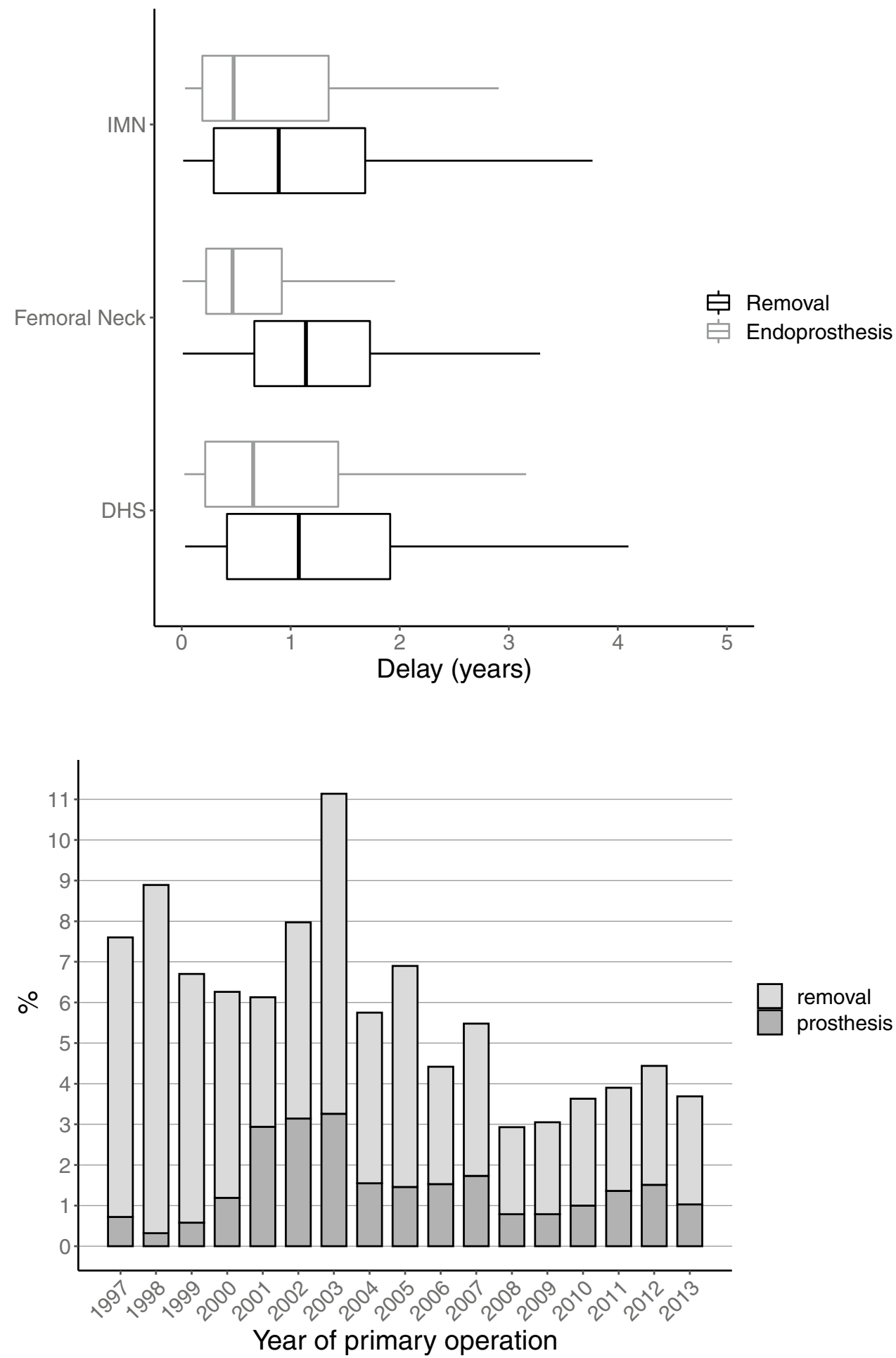
The total removal rates of the fixation material during the first 3 years after the DHS operation decreased slightly (from 5.0\% in 1997 to $4.4 \%$ in 2013) during the study period (Fig. 4). The prosthesis implantation rates after the DHS surgery increased during the study period, from $0.7 \%$ in 1997 to $2.2 \%$ in 2013 .

The total removal rates of the fixation material during the first 3 years after the screw fixation of femoral neck fractures did not show consistent trend changes during the study period (18.2\% in 1997 vs. $17.6 \%$ in 2013) (Fig. 5).
The prosthesis implantation rates after this screw fixation increased during the study period, from $4.8 \%$ in 1997 to $9.2 \%$ in 2016.

\section{Discussion}

This study showed that IMN operations largely replaced DHS operations as the treatment for trochanteric fractures of the proximal femur in Finland during the years 1997
Fig. 4 Total hardware removal and prosthesis rates during the first three years after dynamic hip screw fixation of the trochanteric fracture of the proximal femur
Fig. 5 Total hardware removal and prosthesis rates during the first three years after screw fixation of the fracture of the femoral neck
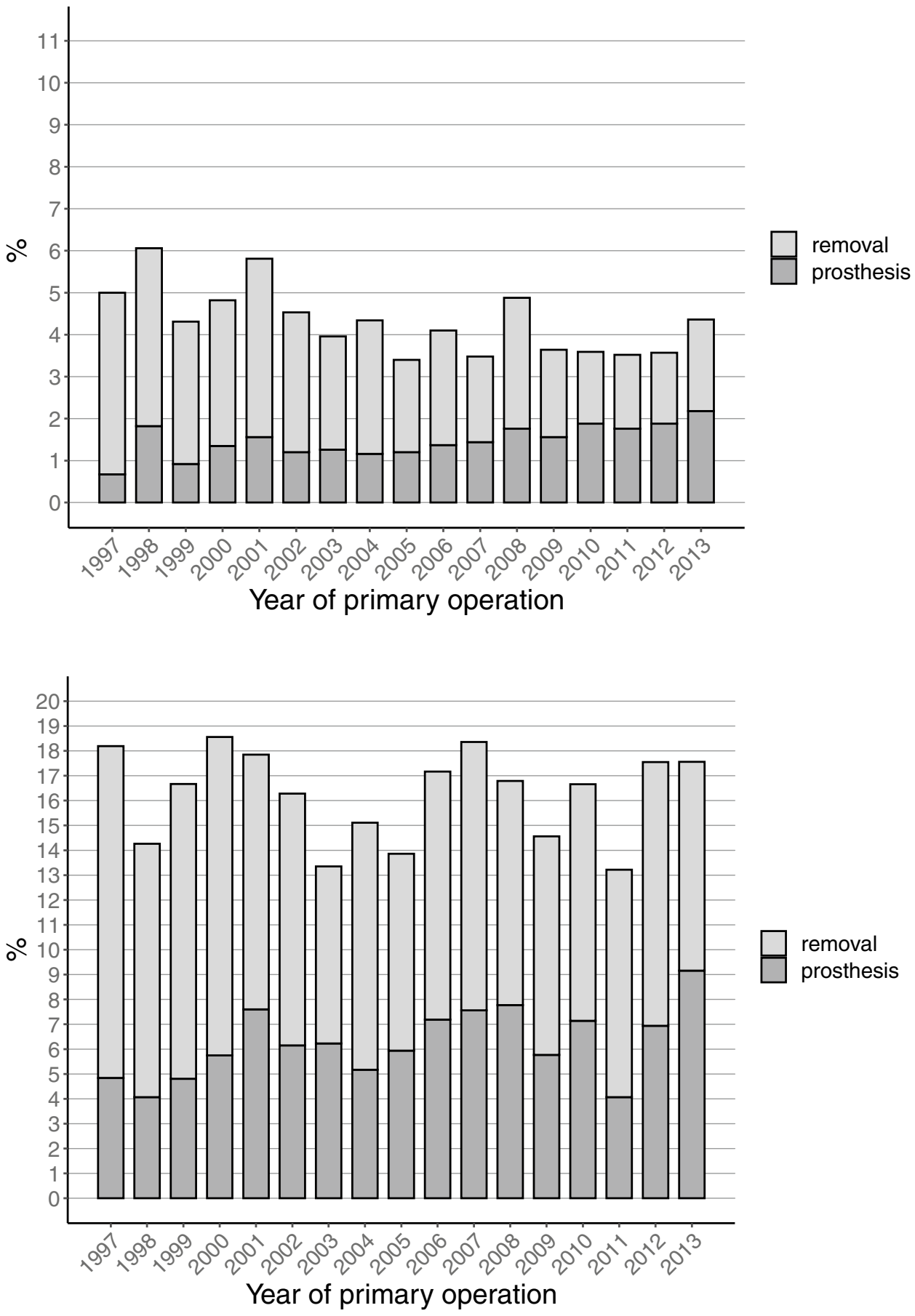
and 2016 while screw fixation of femoral neck fractures decreased during these years. The total removal rates of DHS and IMN were rather similar (5.5\% and 5.4\%), while the total removal rate of screw fixations of femoral neck fracture was clearly higher (18.5\%). The rate of secondary prosthesis operations following DHS and IMN was low (1.8\% for both). This was in clear contrast to the prosthesis rate following screw fixations of the femoral neck fractures (7.2\%).

Historically, various fixation methods have been suggested for treatment of proximal femur fractures $[4,7,14$, 46, 48]. However, problems with failure of the fixation, nonunion, and high mortality encouraged to develop more efficient techniques [7, 14]. Dynamic hip screw (DHS) was introduced for trochanteric fractures to solve the problems regarding nonunion and the results were favorable [46]. When intramedullary nails (IMN) for trochanteric fractures were first introduced, it was noted that the risk for secondary femoral shaft fractures were higher than when using DHS, and therefore it was not at first adapted to routine use [1, 8]. However, recent meta-analyses have shown that the problem with femoral shaft fractures has been resolved and the use of IMN nails does not have a higher risk for complications than DHS [3, 24]. Furthermore, a recent randomized prospective study showed that patients treated with IMN were able to return their pre-surgery walking ability faster than patients treated with DHS [41].

The controversy between internal fixation and primary arthroplasty for optimal treatment of displaced femoral neck fractures has existed for decades [11]. Recent meta-analyses have shown that the primary arthroplasty is slightly superior to internal fixation in terms of revision surgery, infection rate, pain, blood loss and operation time [2, 32, 44]. The results of our study support the findings from these metaanalyses: the incidence of screw fixations of femoral neck fractures declined from 10 per 100,000 person-years in 1997 to 4 per 100,000 person-years in 2016. In other words, it seems that primary arthroplasty is displacing internal fixation as the first-line treatment of displaced femoral neck fractures.

Originally, various adverse effects, such as deep late infection, metal corrosion, pseudotumors and even neoplasia, were proposed to be the result from fixation material, and this doubt led towards routine removals $[5,17,21,28$, 50]. On the other hand, it has been noted that these problems are not commonly related to modern fixation materials and the routine removals of the fixation material have been criticized [9]. As lack of evidence in the literature has remained, the removal rates have varied between professionals and areas $[9,20]$.

Lovald et al. published a study investigating the fracture fixation material removals in the USA during 2007 [31]. In their study, the removal rate was calculated from data of 1 year, and they reported a removal rate of $15.8 \%$.
The most common reasons for the fixation material removals were mechanical complications (18.7\%), osteoarthritis $(14.3 \%)$, nonunion $(13.9 \%)$, refracture $(10.9 \%)$, and other complications (10.1\%) [31]. Interestingly, they also reported that the likelihood of fixation material removal was affected by age, sex and insurance status [31].

In our study, the total removal rate for IMN and DHS of the intertrochanteric fracture was $5.5 \%$, and for screw fixation of the femoral neck fractures $18.5 \%$. The removal rates of all internal fixation methods decreased or stayed relatively stable throughout the years. Thus, our removal rates for IMN and DHS were remarkably lower than previously reported (16\%) [31]. One of the reasons for our lower figures could be that our publicly funded health care system has an intrinsic aim for cost-savings and costeffectiveness thus preferring non-removals.

A remarkable change in our study occurred in IMN removals, which decreased about 50\% between 1997 and 2013. This change seems to be in line with the literature, as no new studies supporting the removals have been published. We also noted a slightly increasing trend that in fractures of the femoral neck the screw fixation material is replaced with an endoprosthesis (Fig. 5). This, however, is a moribund phenomenon since incidence of screw fixation for femoral neck fractures is drastically declining (Fig. 1).

The strength of our study was the nationwide National Hospital Discharge Register which included all fixation operations for proximal femur fractures in Finland between 1997 and 2016. Every patient had a personal ID number and we were able to follow these numbers through the study period. In this way, we could also calculate precise removal rates of the fixation material for the entire surgically treated fracture population. The limitation of this study was that indications for the removals were not registered, and therefore, the exact reasons for the observed removal trends remained unknown.

As a conclusion, IMN operations increased in Finland in 1997-2016 and largely replaced DHS operations as the treatment of choice for trochanteric fractures of the proximal femur. At the same time, screw fixation of femoral neck fractures decreased. The total removal and secondary prosthesis rates of DHS and IMN were similar (total removal rates $5.5 . \%$ and $5.4 \%$, prosthesis rate $1.8 \%$ for both), while the total removal and secondary prosthesis rates of screw fixations of femoral neck fracture were clearly higher (removal rate $18.5 \%$, prosthesis rate $7.2 \%$ ). The total removal rates of the fixation material during the first three years after the IMN operation halved during the follow-up, while the removal rates of DHS and screw fixation for femoral neck fractures did not show any consistent time trend. 
Author contributions VTP: literature search, study design, data analysis, data interpretation, writing. TTH: study design, data collection, critical review, writing. PK: study design, critical review, writing. VM: study design, data collection, critical review, writing.

Funding There is no funding source.

\section{Compliance with ethical standards}

Conflict of interest The authors declare that they have no conflict of interest.

Ethical approval This article does not contain any studies with human participants or animals performed by any of the authors.

Open Access This article is licensed under a Creative Commons Attribution 4.0 International License, which permits use, sharing, adaptation, distribution and reproduction in any medium or format, as long as you give appropriate credit to the original author(s) and the source, provide a link to the Creative Commons licence, and indicate if changes were made. The images or other third party material in this article are included in the article's Creative Commons licence, unless indicated otherwise in a credit line to the material. If material is not included in the article's Creative Commons licence and your intended use is not permitted by statutory regulation or exceeds the permitted use, you will need to obtain permission directly from the copyright holder. To view a copy of this licence, visit http://creativecommons.org/licenses/by/4.0/.

\section{References}

1. Adams CI, Robinson CM, McQueen MM (2001) Prospective randomized controlled trial of an intramedullary nail versus dynamic screw and plate for intertrochanteric fractures of the femur. $\mathrm{J}$ Orthop Trauma 15(6):394-400

2. Bhandari M, Devereaux P, Swiontkowski MF et al (2003) Internal fixation compared with arthroplasty for displaced fractures of the femoral neck: a meta-analysis. JBJS 85(9):1673-1681

3. Bhandari M, Schemitsch E, Jönsson A, Zlowodzki M, Haidukewych GJ (2009) Gamma nails revisited: gamma nails versus compression hip screws in the management of intertrochanteric fractures of the hip: a meta-analysis. J Orthop Trauma 23(6):460-464

4. Bienkowski P, Reindl R, Berry GK, Iakoub E, Harvey EJ (2006) A new intramedullary nail device for the treatment of intertrochanteric hip fractures: Perioperative experience. J Trauma Acute Care Surg 61(6):1458-1462

5. Black J (1988) Does corrosion matter? J Bone Joint Surg Br 70(4):517-520

6. Bostman O, Pihlajamaki H (1996) Routine implant removal after fracture surgery: a potentially reducible consumer of hospital resources in trauma units. J Trauma Acute Care Surg 41(5):846-849

7. Boyd HB, Griffin LL (1949) Classification and treatment of trochanteric fractures. Arch Surg 58(6):853-866

8. Bridle SH, Patel AD, Bircher M, Calvert PT (1991) Fixation of intertrochanteric fractures of the femur. A randomised prospective comparison of the gamma nail and the dynamic hip screw. J Bone Joint Surg Br 73-B(2):330-334

9. Busam ML, Esther RJ, Obremskey WT (2006) Hardware removal: indications and expectations. JAAOS 14(2):113-120

10. Center JR, Nguyen TV, Schneider D, Sambrook PN, Eisman JA (1999) Mortality after all major types of osteoporotic fracture in men and women: an observational study. Lancet 353(9156):878-882

11. Chua D, Jaglal SB, Schatzker J (1997) An orthopedic surgeon survey on the treatment of displaced femoral neck fracture: opposing views. Can J Surg 40(4):271

12. Court-Brown CM, Caesar B (2006) Epidemiology of adult fractures: A review. Injury 37(8):691-697

13. Fielden J, Purdie G, Horne G, Devane P (2001) Hip fracture incidence in New Zealand, revisited. N Z Med J 114(1129):154

14. Fielding JW (1973) Subtrochanteric fractures. Clin Orthopaed Relat Res 92:86-99

15. Finsen V, Benum $P$ (1986) Refracture of the hip rare after removal of fixation device. Acta Orthop Scand 57(5):434-435

16. Finsen V, Johnsen LG, Tran $\varnothing$ G, Hansen B, Sneve KS (2004) Hip fracture incidence in central Norway: a followup study. Clin Orthopaed Relat Res 419:173-178

17. French HG, Cook SD, Haddad RJ Jr (1984) Correlation of tissue reaction to corrosion in osteosynthetic devices. J Biomed Mater Res 18(7):817-828

18. Gabriel SE, Gabriel SE, Tosteson ANA et al (2002) Direct medical costs attributable to osteoporotic fractures. Osteoporos Int 13(4):323-330

19. Gösling T, Hufner T, Hankemeier S, Zelle BA, Muller-Heine A, Krettek C (2004) Femoral nail removal should be restricted in asymptomatic patients. Clin Orthopaed Relat Res 423:222-226

20. Hanson B, van der Werken C, Stengel D (2008) Surgeons' beliefs and perceptions about removal of orthopaedic implants. BMC Musculoskelet Disord 9(1):73

21. Highland TR, LaMont RL (1985) Deep, late infections associated with internal fixation in children. J Pediatr Orthop 5(1):59-64

22. Huusko T, Karppi P, Avikainen V, Kautiainen H, Sulkava R (1999) The changing picture of hip fractures: dramatic change in age distribution and no change in age-adjusted incidence within 10 years in Central Finland. Bone 24(3):257-259

23. Johnel O, Gullberg B, Allander E, Kanis J, Group MS (1992) The apparent incidence of hip fracture in Europe: a study of national register sources. Osteoporos Int 2(6):298-302

24. Jones HW, Johnston P, Parker M (2006) Are short femoral nails superior to the sliding hip screw? A meta-analysis of 24 studies involving 3279 fractures. Int Orthop 30(2):69-78

25. Kannus P, Niemi S, Parkkari J, Sievänen H (2018) Continuously declining incidence of hip fracture in Finland: analysis of nationwide database in 1970-2016. Arch Gerontol Geriatr 77:64-67

26. Kannus P, Sievänen H, Palvanen M, Järvinen T, Parkkari J (2005) Prevention of falls and consequent injuries in elderly people. Lancet 366(9500): 1885-1893

27. Keskimaki I (1991) Accuracy of data on diagnosis, procedures and accidents in the Finnish hospital register. Int J Health Sci 2:15-21

28. Kreicbergs A (1983) Pseudotumor after metal fixation of a fracture surgery: a case report. Acta Orthop Scand 54(5):739-742

29. Kröger H, Huopio J, Honkanen R et al (1995) Prediction of fracture risk using axial bone mineral density in a perimenopausal population: a prospective study. J Bone Miner Res 10(2):302-306

30. Lau E, Cooper C, Fung H, Lam D, Tsang K (1999) Hip fracture in Hong Kong over the last decade-a comparison with the UK. J Public Health 21(3):249-250

31. Lovald S, Mercer D, Hanson J et al (2012) Hardware removal after fracture fixation procedures in the femur. J Trauma Acute Care Surg 72(1):282-287

32. Lu-Yao GL, Keller RB, Littenberg B, Wennberg JE (2005) Outcomes after displaced fractures of the femoral neck. A meta-analysis of one hundred and six published reports. Orthoped Trauma Direct 3(03):29-33

33. Lüthje P, Kataja M, Nurmi I, Santavirta S, Avikainen V, Läike E (1992) Hip fractures in urban population in Finland. Ann Chir Gynaecol 81(3):316-321 
34. Mattila VM, Sillanpaa P, Iivonen T, Parkkari J, Kannus P, Pihlajamaki $\mathrm{H}$ (2008) Coverage and accuracy of diagnosis of cruciate ligament injury in the Finnish National Hospital Discharge Register. Injury 39(12):1373-1376

35. Melton LJ (1993) Hip fractures: a worldwide problem today and tomorrow. Bone 14:1-8

36. Melton LJ, Gabriel SE, Crowson CS, Tosteson ANA, Johnell O, Kanis JA (2003) Cost-equivalence of different osteoporotic fractures. Osteoporos Int 14(5):383-388

37. Miyamoto RG, Kaplan KM, Levine BR, Egol KA, Zuckerman JD (2008) Surgical management of hip fractures: an evidence-based review of the literature. I: Femoral neck fractures. J Am Acad Orthopaed Surg 16(10):596-607

38. Nilsson R, Löfman O, Berglund K, Larsson L, Toss G (1991) Increased hip-fracture incidence in the county of Östergötland, Sweden, 1940-1986, with forecasts up to the year 2000: an epidemiological study. Int J Epidemiol 20(4):1018-1024

39. Nungu S, Olerud C, Rehnberg L (1993) The incidence of hip fracture in Uppsala County: change of time trend in women. Acta Orthop Scand 64(1):75-78

40. Orimo H, Hashimoto T, Sakata K, Yoshimura N, Suzuki T, Hosoi T (2000) Trends in the incidence of hip fracture in Japan, 1987-1997: the third nationwide survey. J Bone Miner Metab 18(3):126-131

41. Pajarinen J, Lindahl J, Michelsson O, Savolainen V, Hirvensalo E (2005) Pertrochanteric femoral fractures treated with a dynamic hip screw or a proximal femoral nail. J Bone Joint Surg Br 87-B(1):76-81

42. Parkkari J, Kannus P, Niemi S et al (1994) Increasing age-adjusted incidence of hip fractures in Finland: the number and incidence of fractures in 1970-1991 and prediction for the future. Calcif Tissue Int 55(5):342-345
43. Ray NF, Chan JK, Thamer M, Melton LJ III (1997) Medical expenditures for the treatment of osteoporotic fractures in the United States in 1995: report from the National Osteoporosis Foundation. J Bone Miner Res 12(1):24-35

44. Rogmark C, Johnell O (2006) Primary arthroplasty is better than internal fixation of displaced femoral neck fractures: a meta-analysis of 14 randomized studies with 2289 patients. Acta Orthop 77(3):359-367

45. Rogmark C, Sernbo I, Johnell O, Nilsson J-Å (1999) Incidence of hip fractures in Malmö, Sweden, 1992-1995: a trend-break. Acta Orthop Scand 70(1):19-22

46. Ruff ME, Lubbers LM (1986) Treatment of subtrochanteric fractures with a sliding screw-plate device. J Trauma 26(1):75-80

47. Rutkow I (1986) Orthopaedic operations in the United States, 1979 through 1983. JBJS 68(5):716-719

48. Simmermacher RKJ, Bosch AM, Van der Werken C (1999) The AO/ASIF-proximal femoral nail (PFN): a new device for the treatment of unstable proximal femoral fractures. Injury 30(5):327-332

49. Sund R (2012) Quality of the Finnish Hospital Discharge Register: A systematic review. Scand J Public Health 40(6):505-515

50. Ward JJ, Thornbury DD, Lemons JE, Dunham WK (1990) Metalinduced sarcoma. A case report and literature review. Clin Orthopaed Relat Res (252):299-306

Publisher's Note Springer Nature remains neutral with regard to jurisdictional claims in published maps and institutional affiliations. 